\section{Homens e mulheres: o imaginário sobre a esterilidade na América portuguesa}

Men and women: imagery about sterility in Portuguese America

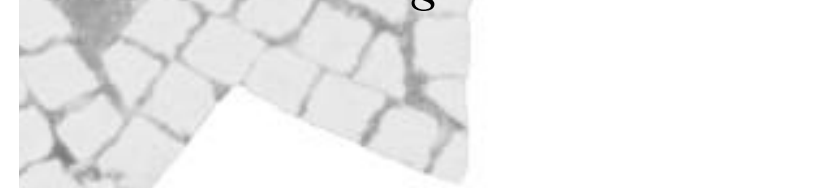

Mary Del Priore

Professora de história da Universidade de São Paulo e da Pontifícia Universidade Católica do Rio de Janeiro Avenida Rui Barbosa, 480/1302 22250-020 Rio de Janeiro - RJ Brasil mdpriore@highway.com.br
DEL PRIORE, M.: 'Homens e mulheres: o imaginário sobre a esterilidade na América portuguesa'.

História, Ciências, Saúde - Manguinhos, vol. VIII(1): 98-112, mar.-jun. 2001.

Este artigo trata dos usos e costumes em torno da esterilidade no Brasil Colônia. Vivida como uma maldição que se abatia mais comumente sobre as mulheres, a esterilidade era combatida com práticas simbólicas e medicina fitoterápica, com o objetivo de "desobstruir" ou "desenfeitiçar" o berço da criação.

PALAVRAS-CHAVE: sexualidade, história do corpo, impotência, esterilidade, medicina popular, Brasil Colônia.

DEL PRIORE, M.: 'Men and women: imagery about sterility in Portuguese America'. História, Ciências, Saude - Manguinhos, vol. VIII(1): 98-112, Mar-June. 2001.

This paper discusses old usages and beliefs about sterility in Colonial Brazil. Treated as a curse usually befallen women, sterility was struggled with symbolism and phytotherapy, aiming to "unblock" or "remove the spell" from the craddle of creation.

KEYWORDS: sexuality, history of body, impotency, sterility, popular medicine, Colonial Brazil. 
Segundo dois pesquisadores franceses (Bajos e Bozon, 1999), desde $\checkmark$ a chegada do Viagra no mercado, o discurso público sobre a sexualidade mudou visivelmente de tom. A pílula milagrosa do prazer, segundo eles, tomou o lugar do preservativo que limitaria o prazer, mas que também protegeria da morte. No Brasil, desde o seu lançamento, o Viagra vem mantendo-se na ponta de lança da mídia, com destaques na imprensa falada e escrita. Mais além da viragem no discurso sobre a sexualidade, como explicar o interesse, as reações e as esperanças suscitadas pelo Viagra? Se essas revelam as grandes mudanças nos comportamentos, traduzem também imobilidades e permanências extremamente duráveis.

Para entender estruturas que foram mais antigas, e são ainda muito profundas, comecemos pelas mais recentes. Nos últimos trinta anos, graças à pílula anticoncepcional, uma transformação sexual 'silenciosa' teve lugar, conduzindo as mulheres a ser mais ativas nas relações sexuais, mais exigentes em relação aos seus parceiros, levando-as, além disso, a prolongar sua vida sexual. Mais freqüentemente que nossos antepassados, vivemos, hoje, homens e mulheres, uma sexualidade assertiva que desejamos fazer durar para além do limite biológico-social da menopausa ou da andropausa. Esse alongamento da vida sexual inscreve-se na revolução que transformou o sexo em fonte de bem-estar e prazer, diferentemente do que significou para nossos ancestrais: medo, culpa ou problema moral. Mas se tal revolução instaurou práticas mais igualitárias entre os parceiros e os sexos, ela não varreu a assimetria profunda do lugar do desejo de homens e mulheres na atividade sexual. Quando da realização do ato sexual, desejo e excitação física continuam percebidos como domínio e responsabilidade exclusiva dos homens. Ora, essa obrigação de virilidade sempre se revelou, ao longo da história, como portadora de profunda ansiedade (Darmon, 1988). A contrapartida era a obrigação feminina de demonstrar fecundidade através de múltiplas gravidezes, contrapartida, diga-se, igualmente, geradora de ansiedade e temores.

Mudanças? Poucas. Homens e mulheres, por exemplo, reconhecem ainda com grande dificuldade a existência e a autonomia do desejo sexual feminino como se o jogo erótico destas últimas tivesse que se esconder por trás da afetividade. A descoberta do Viagra e a acolhida que esse recebeu traduzem bem a transformação e as novas expectativas em relação à sexualidade, mas também - e convém frisá-lo - uma persistência do desejo dos homens. Sempre foram eles que determinaram, pelos sinais da ereção, o momento do coito.

Como demonstrou Foucault (1976), bem antes de se tornarem discursos públicos ou casos de saúde pública - passando lentamente de "frigidez" a "pane sexual" e desta à disfunção erétil -, os comportamentos quotidianos em relação à impotência medravam na esfera da magia analógica, da teologia e da incipiente medicina. Trezentos anos atrás, como veremos, o Viagra era de outra natureza. A angústia, 
contudo, nascida da obrigação de virilidade, já estava profundamente arraigada em nossa cultura. Darmon (op. cit.) foi o primeiro a sublinhar que a sociedade ocidental não era machista apenas com as mulheres: era-o, também, com os homens. Provas históricas? Um breve papal, datado de 1587, definia a impotência masculina como um "impedimento público" ao sacramento do matrimônio. Na França, por exemplo, os processos contra os maridos "frígidos" foram legião entre os séculos XVI e XVIII. Na Espanha do século XVII, acumularam-se poemas nos quais a "agudeza" descrevia em detalhes como era árduo o encontro de corpos marcados por dificuldades sexuais. Em Portugal, em novembro de 1668 , teve início o processo de anulação do casamento de $\mathrm{d}$. Afonso VI com d. Maria Francisca Isabel, duquesa de Sabóia. O golpe de misericórdia vibrado pela rainha contra o rei veio na forma de uma carta em que essa acusava, sem rodeios, o marido: "Rei e Senhor; Deixei minha pátria, vendi minha fazenda por vir buscar a V. Majestade e servi-lo; Não se agradou V. Majestade de mim, não é meu marido como V. Majestade bem sabe" (Serrão, s. d., p. 200).

$\mathrm{Na}$ América portuguesa, as Constituições Primeiras do Arcebispado da Bahia, impressas em 1720, fonte da regulamentação moral no período colonial, não deixavam dúvidas: a impotência era causa de anulação matrimonial: quando algum contraente, já antes de contrair matrimônio, "não era capaz de geração por falta ou desproporção dos instrumentos da cópula ou a falta provenha da natureza, arte ou enfermidade, contanto seja perpétua”.

Mas a pergunta do historiador é: como se vivia no passado a maldição da impotência? Que cuidados existiam para aprimorar a então chamada “obra de Vênus"? Graças a Camporesi (1990), sabemos que a potencialização da luxúria tinha função explícita: restaurar o arsenal sexual do amante, solicitar, acordar e excitar o apetite viril. Isso, pois nessa cultura e nesses tempos, o sentido da vida e a presença humana ativa sobre o teatro do mundo passava pela medida de virilidade e fecundidade. Virilidade e fecundidade eram teste fundamental quanto à capacidade de interpretarem, homens e mulheres, seu próprio papel na cena das representações insidiosas da carne. Insidiosas, porém necessárias. Afinal, "o crescei e multiplicai-vos" era obrigatório e a Bíblia já o tinha estipulado.

Sublinha Carneiro (1994) que essa preocupação foi estrutural na sociedade ocidental cristã. Só que, na Idade Média, os limites entre virilidade, fecundidade e os desdobramentos do desejo sexual excessivo ainda não tinham sido de todo demarcados. Os filtros do amor, por exemplo, alimentaram a literatura do renascimento medieval. $\mathrm{O}$ exemplo máximo é a estória de Tristão e Isolda, onde a poção mágica tem decisiva importância na trama que leva a heroína aos braços do herói. No século XII, o filtro é considerado um instrumento legítimo do desejo. Mas uma viragem ocorreu. $O$ casamento monogâmico e indissolúvel, tal como foi instituído pela Igreja Católica no século XII, 
era considerado um remédio contra a concupiscência. Seu objetivo fundamental era a procriação e os filhos; a felicidade e o desejo eram secundários. Prova disso é que, um século mais tarde, uma acirrada repressão se abateu sobre práticas afrodisíacas baseadas em poções, sua condenação explicitando-se até no Manual dos inquisidores de Eymerich (1376).

Segundo Carneiro, nos registros da colonização portuguesa, tanto na Ásia quanto na América, os afrodisíacos aparecem tanto que nos fazem crer que fossem buscados com insistência. Era como se, no início da Idade Moderna, tanto a tradição afrodisíaca quanto aquela outra, normativa recém-instaurada, ainda estivessem largamente imbricadas. Orta (1891), autor seiscentista português, preocupa-se em registrar, nas suas observações de naturalista, tudo que pudesse dizer respeito à disfunção ou ao aprimoramento das funções sexuais. Ele menciona o âmbar, "bom para conversação com mulheres"; a "assafétida", para "levantar o membro" e para as "festas de Vênus"; as cubebas para "ajudar a Vênus" e o bétel "que para as bodas de Vênus é principal alcoviteiro”. Mesmo o ópio, conhecido como anfião, segundo um surpreso Orta era usado com fins luxuriosos, pois embora "os físicos todos letrados me afirmavam tornava os homens impotentes", confessa, ele deixava os homens "fora de si" estimulando a "virtude expulsiva", ou seja, aquela que "deita nos testículos a virtude genital". Comia-se ópio para prolongar o prazer sexual, ou, como se dizia então, "para acabar o auto venéreo mais tarde". A banana e o figo, segundo o mesmo autor, possuíam, por virtudes analógicas óbvias com as partes sexuais masculinas, as mesmas virtudes de "excitar a deleitação carnal". A jaca assada com castanhas, idem, segundo Cristovão de Acosta. O bangüê, ou maconha, era mastigada para ajudar o "ato venéreo" ou ingerida em pó, misturada a cravo e noz-moscada. A própria pimenta, especiaria responsável pelo comércio ultramarino, permitia associar o ardor do alimento com a inflamação erótica, sendo considerada "fumacenta e penetrativa ... prejudicial à saúde, maiormente da alma porque provoca a sensualidade" (Carneiro, op. cit., p. 90). Perfumes e odores, como o almíscar, extraído do castor, ou o âmbar gris, extraído do intestino de cachalotes, aproveitavam-se muito para a "conversação com mulheres", e o século XVII, o mesmo que assistiu a uma avalancha de processos contra impotentes, assistiu, também, ao desenvolvimento de polvilhos, contas, incensos, pastilhas, águas odoriferas com nítida referência afrodisíaca.

A preocupação que sempre segue à descrição de tais produtos era, contudo, de ordem moral. Diferentemente do que ocorria na Idade Média, o excesso do consumo de afrodisíacos passa a ser severamente condenado. É importante também lembrar que, pelo menos durante o Renascimento, se a reprodução era assunto importante para médicos e teólogos, a chamada "cópula carnal" revestia-se, no entender dos mesmos, de grandes riscos. Considerava-se a mulher - é bom não 
esquecer - um acólito de Satã e portadora de uma porta úmida que se abria para o inferno. Acreditava-se que o obscuro golfo da vagina escondia, em suas águas lívidas, seivas nefastas impregnadas de pecado e doenças ignóbeis. A "sombria caverna”, o pântano pútrido, abrigava o membro considerado por Aristóteles inobediente a sua dona. Não é à toa que cronistas e os primeiros médicos que vêm para a América portuguesa, como Guilherme Piso, registrariam que excessos libidinosos comuns entre indígenas ou mazombos levavam a "perpétuas vigílias" e febres. Culpa das mulheres e das obras de Vênus. (idem, ibidem, p. 98).

Segundo Carneiro, esta visão torna-se mais densa a partir do século XVII, momento em que, num contraste evidente com textos médicos botânicos do século XVI, "o serviço de Vênus" ou a luxúria passa a ser atacada. Mais: ela passa a ser medicalizada. Além de pecado, será considerada enfermidade. Não obstante, afirma o mesmo autor, as plantas incitadoras dos sentidos sensuais continuam a ser registradas em algumas obras. Entre elas acha-se a prosaica hortelã - "esta erva é quente e seca ... é boa para dores de cólica, de estômago, do útero e da cabeça; provoca atos libidinosos", informa Henriques (1731, p. 359); "os nabos são quentes e úmidos, cozem-se com facilidade e nutrem pouco ... pelo seu calor e flatulência incitam a atos libidinosos"; "a cenoura ... quente e seca" incitava a natureza para o serviço de Vênus.

Como bem diz Carneiro, questões relativas à potência sexual percorreram, durante a Idade Moderna, a região fronteiriça entre pecado, doença e vício. $\mathrm{O}$ uso de plantas para fins libidinosos era evidenciado na importância dos ungüentos e filtros e na perseguição de benzedeiras, curandeiros e bruxas, que os empregavam na magia capaz de tornar qualquer um impotente (Freyre, 1980; Mello e Souza, 1988). Desde o século VII, quando Isidoro de Sevilha registrou o uso de uma planta chamada satyrion - "assim chamada pelo incêndio libidinoso que produz” - até o século XVIII, quando a satiríase será diagnosticada como uma doença, a arte da afrodísia sofrerá perseguições. Se os cronistas quinhentistas registravam o uso suntuoso dos aromas e dos óleos para fins sensuais com insistente curiosidade, os médicos dos séculos posteriores condenavam cada vez mais os mesmos procedimentos. Em 1629, Aleixo de Abreu descreverá, de forma exemplar, a seqüência de doenças que sofreu quando uma inflamação do fígado foi seguida por outra de rins, depois por uma satiríase até chegar à febre. Instalada inicialmente em vários órgãos, ao atingir o sexo, a doença tornava-se violento e compulsivo desejo.

Como terapia - é sempre Carneiro (op. cit., p. 102) quem nos informa -, Aleixo tentaria debelar a doença do desejo com as mesmas sangrias que recomendava para outras doenças, pois seria "o grave calor do sangue" que causaria o "incêndio no lombo", aquecimento de artérias e enviando "espíritos ao membro". Relatar como foi acometido de satiríase e o modo pelo qual se curou, não era incomum. Errado 
seria não ter diagnosticado a natureza de um mal no enrijecimento do seu próprio pênis, pois não sendo doença, tal coisa só podia ser luxúria. Luxúria condenável em qualquer cristão e mais ainda num médico, pois como dizia Brás Luís de Abreu (1726, p. 734): "deixa de ser médico, se é lascivo".

Outras 'doenças' sexuais também fazem sua aparição. A "erotomania ou a melancolia amorosa", mal moderno a atingir homens e mulheres obcecados com questões de virilidade e fecundidade, era combatida com sangrias copiosas, realizadas nos braços, nos pés ou atrás das orelhas. João Curvo Semedo preferia a essas corações de ratos domésticos e ouro puríssimo (Pereira, 1980, p. 43). Dietas eram obrigatórias e delas varriam-se todos os alimentos "quentes", baseados em especiarias e condimentos como as já mencionadas pimentas. Os fármacos empregados eram de natureza "fria e úmida", visando apagar o incêndio da carne. Essa doença, chamada "febre amorosa", era descrita nos seguintes termos:

Nossos modernos práticos chamam febre amorosa os batimentos do coração, inchamento do rosto, apetites depravados, tristeza, suspiros, lágrimas sem motivo, fome insaciável, sede raivosa, síncopes, opressões, sufocações, vigílias contínuas, cefalalgias, melancolias, epilepsia, raivas, furores uterinos, satiríases e outros perniciosos sintomas que não recebem mitigação nem cura na maior parte das vezes do que pelos remédios do amor (Ferrand, 1623, p. 264).

Sua causa pode ser tanto um veneno como um remédio ou filtro amoroso. Esse mal, apresentado como um guerreiro que conquista uma fortaleza, explica Carneiro (op. cit.), ataca inicialmente pelos olhos, flui pelas veias como um veneno, chegando ao fígado, que inflama de forma a transmitir um calor aos rins e ao lombo, que se tornam sedes importantes do sistema erótico, chegando finalmente ao cérebro, então, escravizado:

O amor tendo abusado dos olhos, como verdadeiros espiões e porteiros da alma, deixa-se deslizar docemente por um par de canais e caminha insensivelmente pelas veias até o fígado, imprime subitamente um desejo ardente da coisa que é ou parece amável, acende a concupiscência e por este desejo começa toda a sedição ... vai diretamente ganhando a cidadela do coração, o qual, estando uma vez mais assegurado como o mais forte lugar, ataca depois tão vivamente a razão e todas as potências nobres do cérebro, que ela se sujeita e torna-se totalmente escrava (idem, ibidem, p. 218).

Para evitar tal febre, evitava-se dormir de costas, tomavam-se banhos gelados e usavam-se remédios frios e úmidos, como águas de alface 
e grãos de cânfora. Costumava-se untar rins, pênis e períneo com ungüentos feitos de ervas "muito frias". Os médicos do período preocupavam-se tanto com os excessos da luxúria quanto com a temida impotência. Confundindo o medo da segunda com os excessos da primeira, em ambos os casos, as dúvidas recaíam sempre sobre um mesmo diagnóstico: "o diabo, autor de toda a maldade, pode resfriar os amores lícitos e acender os ilícitos".

Esse tipo de asserção era comum. Sabemos que o corpo físico, no passado e mais precisamente durante a Idade Moderna, era visto como o palco nebuloso onde Deus e o Diabo se digladiavam. As doenças, e entre elas a impotência, eram consideradas desregramentos do espírito punidos com o açoite divino ou um mal demoníaco ou feitiço diabólico. Esse imaginário, que tornava o corpo um extrato do céu ou do inferno, constituía-se num saber capaz de orientar a medicina, suprindo provisoriamente as lacunas de seus conhecimentos (Del Priore, 1998, pp. 78-114). No século XVII, a medicina que era praticada em Portugal ou em seus domínios no além-mar ecoava as diretrizes da Igreja, no sentido de adequar o uso da sexualidade ao casamento. Inúmeras prescrições afloravam nos textos de médicos letrados ou paramédicos, cujas observações bracejavam no desconhecimento da ciência médica. Num clima de crenças e superstições extremamente arraigadas no que diz respeito ao uso e aos cuidados com o corpo, proliferava um saber que se valia de analogias, esconjuros e benzeduras, drogas e elixires afamados.

Eis por que Pereira (1734, pp. 242-3, 430) medicaliza com tanta insistência a luxúria - sublinhe-se, outrora, um pecado, agora, doença - que sua descrição menciona literalmente sintomas, delírio, contágio, infecção: "aquele fogo ou febre ardentíssima que introduz na alma infernais incêndios, somente se apaga e se modera com o uso da oração e penitência, com a lembrança e consideração do inferno ... se acaso há tardança nessa aplicação, degenera em terribilíssimos sintomas e na maior parte das vezes imedicáveis, pois passa a delírio, que descompõem a honestidade dos costumes, e a contágio, que infecciona a pureza dos afetos”. E, concluindo, faz a analogia simbólica da medicalização do pecado, considerando estar a origem das doenças no ato rebelde de Adão: "ao pecado do primeiro homem, chama a Igreja peste mortal ... para te curar desta tua enfermidade, veio do céu à terra o Divino Médico ... aplicou a tua doença o maior remédio ... um lavatório não de água elementar, mas sim de seu próprio sangue preparado na Botica do calvário ... para te curar das recaídas deixou na Igreja sete remédios receitados que foram os sete sacramentos". E o enfermo, "tocado da peste do pecado, deve procurar médico sacerdote para the confeccionar este emplastro saudável para a sua alma, como triaca medicinal, que haja de extinguir o veneno do pecado; para o que deve dar inteira conta e verdadeira informação de toda a doença que padece e dos sintomas que o oprimem”. Bem diz Carneiro (1994, p. 
105) que o texto de Pereira expõe de forma exemplar a fusão entre a confissão e o interrogatório médico, o pecado e a doença, o confessor e o médico.

A presença da impureza moral ou física no quadro da vida conjugal erigia-se então como termômetro para o coito, fazendo da esterilidade feminina um estigma. $\mathrm{O}$ excesso de interesse pelo sexo, visto como "desordenamento" por padres e médicos, tanto podia atrasar quanto impedir uma gravidez, e estava associado pelos tratadistas a um castigo de Deus às mulheres lascivas. Em nome da sacralidade e dos fins do matrimônio, a impotência de ambos os sexos constituía-se, aos olhos da Igreja, em "impedimento dirimente", levando à anulação do mesmo. Nicolas Venette, autor do importante La génération de l'homme ou Tableau de l'amour conjugal, obra de 1696, repetia os antigos afirmando que as mulheres eram mais responsáveis pela esterilidade do que os homens (apud Darmon, 1981, p. 27). Sua opinião encontrava respaldo em presunções populares, correntes nos séculos XVI e XVII, de que as mulheres muito bonitas eram impotentes por castigo divino, irado com suas vaidades. E as muito feias também o eram, num castigo divino, por sua inveja das bonitas.

Mas é bem distante dos debates entre Igreja e medicina que o historiador encontra restos da preocupação que se tinha, no passado, com a esterilidade e na ênfase dada pelas comunidades do passado à questão da procriação. Outrora, espaço onde se amalgamavam crenças em malefícios, influências cosmológicas e magia, as práticas contra a esterilidade revelavam a resistência das populações à eliminação de práticas ancilares que traduziam o controle de homens e mulheres sobre o seu próprio capital seminal. A solidez de crenças e de uma mentalidade havia séculos enraizada, ainda que mediada pelos "doutores", esclarece que a eficácia de rituais de combate à esterilidade tinha sua fonte num saber analógico. Pereira (1734, p. 232), por exemplo, ao explicar a "frigidez", incorporava elementos mágicos e teológicos a sua "observação científica":

A impotência, geralmente falando, ou é para não poder gerar, que é a que dá nas pessoas estéreis e infecundas; ou é para não poder coabitar, que é a que se acha nos estatutos canônicos. Chamam frios (os estéreis e infecundos). Esta segunda, ou é perpétua, que não se pode remediar nem por indústrias da medicina, nem por benefícios de remédios eclesiásticos, ou é temporal, que deixa por tempo determinado; esta se subdivide mais em impotência absoluta, que é a que se dá em um homem para todas as mulheres, ou nestas para todos os homens; e em respectiva que é a que se dá com respeito a um homem ou mulher determinada; e esta finalmente ou provém de causa natural somente, ou de malefício.

Ou seja, estéreis e frios podiam sofrer de impotência perpétua ou temporária. Mais, essa "frialdade" podia ser respectiva, tendo como 
alvo o cônjuge; ou absoluta, quer dizer, de uma mulher ou homem em relação aos demais membros do outro gênero. A crença generalizada, que explicava, aliás, a impotência de tipo "respectivo ou absoluto" era a maldade do demônio. Demônio esse capaz de ligar, por arte satânica, as partes sexuais, incapacitando-as para os seus movimentos naturais. Ora, o grande número de mezinhas receitadas aos "ligados" ou impotentes "por malefício", encontrado em manuscritos na Biblioteca Nacional do Rio de Janeiro, sublinhava a concepção mágica que se tinha nesse período sobre a procriação. Pouco importavam as explicações médicas, mais valendo a simbologia analógica de certos medicamentos de uso tradicional.

O comer "pegas assadas e cozidas", ave corvídea também conhecida por pica-pica, e a erva "hipericão" aplicada aos rins, ajudava.

Ir urinar num cemitério pela argola da campa de uma sepultura, urinar pelo anel da esposa antes, e depois do ajuntamento, ou pelo nó de uma ripa, ou tábua cortada ... da água que cair da boca de qualquer cavalo que beber em corrente apanhada, logo escrevem alguns há grande virtude. ... Tomar erva de carrapatos ou figueirado-inferno e metida em uma panela nova se lhe lance em cima urina do doente e depois de cozida se enterre em parte, ou lugar fora do caminho, porque o feitor do malefício sentirá grandes dores, e estimulado disto desfará o malefício (idem, ibidem, p. 234).

Tanto em Portugal quanto na Colônia vivia-se na crença de poderes demoníacos sobre o corpo e a sexualidade, rastreados, aliás, por todos os manuais inquisitoriais de demonologia, os quais exigiam medidas combativas contra a esterilidade. Eis por que as já citadas Constituições do Arcebispado da Bahia mencionam a impotência "por arte", referindose às artes de Satã. Além de buscar a neutralização do mal, tais receitas, quando não eram eficientes, serviam como desculpa para esposos interessados em reverter o quadro de indissolubilidade matrimonial alegarem o não-cumprimento do débito conjugal. Para os menos impressionáveis recomendava-se que

os ligados, abstendo-se do congresso alguns dias, recorressem a Deus Nosso Senhor com deprecações para que por seu Filho Unigênito, Nosso Senhor Jesus Cristo, fosse servido destruir as obras do Demônio; ... que se inquirissem e revolvessem os cantos, cama, casa e couceiros das portas, e achando-se alguns instrumentos, se queimassem e mudassem ao menos o leito e a cama ... e que se purgassem com os remédios adequados ao humor em que residia o venéfico ... bebendo-se em cima um pouco de vinho generoso, e passada hora coabitassem, com os quais remédios se reduziriam ao estado antigo e cessará o venéfico (idem, ibidem, p. 235). 
${ }^{1}$ A algália era medicamento extraído de excremento animal (sobre o assunto ver Mário de Andrade, 1980). Ver também Semedo (1720, p. 148).
Para aqueles que quisessem tão-somente conjurar os riscos do malefício, vivendo em "amor pacífico", recomendava-se ao marido "trazer consigo o coração da gralha macho, e à mulher o da gralha fêmea”. E, finalmente, para aqueles que quisessem testar suas sinceras afinidades, uma fórmula que conciliava aos que "se tratam com amizade recíproca, e aos que se aborrecem, aumenta a inimizade": "os pós de andorinhas vivas em uma panela a torrar no forno dadas a beber em vinho".

Encorajadas ou condenadas pela medicina, essas práticas tinham em comum o fato de realçar as partes do corpo, cujas conotações sexuais eram valorizadas por registros simbólicos. O mesmo médico luso, Bernardo Pereira, sugeria aos ligados: "Lavar as partes pudendas com cozimento da semente, flor e erva chamada vulgarmente pombinha, defumando depois com dente de defunto lançado em tijolo feito brasa, maciando-o quando em quando em aguardente, e depois de limpo o suor untar com assa-fétida, embrulhando as partes (sexuais) em panos quentes defumados no mesmo". Aconselhava também defumadoiros à base de "pós de rasuras dos sinos raspados onde dá o badalo", tomados com "pós de genital de touro".

As unções com fel (fezes) de corvo ou de cão, os untos de "pardal e enxúndia de cegonha” e os banhos íntimos com açafrão, noz-moscada, carne de vitela, leite e vinho eram de uso recorrente. Inspirado em Garcia de Orta, que destacara os resultados da assa-fétida (para alguns autores, asa de morcego, para outros, uma planta da família das umbelíferas) "para levantar o membro", Curvo Semedo (1707, p. 235) recomendava um óleo em que "tivessem infundido cinqüenta formigas que têm asas" e Sabugo (1734, p. 224) pedia atenção para "manjares que comem marido e mulher ... porque a fôrma sempre retém alguma coisa da matéria". Desaconselhados eram os "maus mantimentos, nem coisas fleumáticas, nem melancólicas, ao tempo que há aptidão na mulher para emprenhar, para que a semente seja de boa matéria". Entre os "casados frios e velhos", havia esperança para os que untassem "levemente o membro, e principalmente a fava, com uma migalha de algália ... porque acodem tantos espíritos a ela e a engrossam de sorte que alguma vez não pode sair do vaso (feminino)". ${ }^{1}$

Araújo (1961, p. 155) lembra bem que o contato com os índios na América portuguesa levou ao emprego da pirótica, ou seja, o uso do fogo, nos procedimentos de cura. Homens, cuja impotência causavalhes dissabores e vergonha, untavam o escroto e a região púbica com sebo de bode, "sentando-se sobre brasas vivas", isto é, aproximandose, o mais possível, de um "caco" (vasilha de barro em forma de alguidar) cheio de brasas. Provavelmente de tal prática, informa-nos o mesmo autor, nasceu a expressão "estar sentado em brasas". Garrafadas à base de catuaba, largamente utilizadas até os dias de hoje, também decorrem dos empréstimos aos conhecimentos fitoterápicos dos tupisguaranis. 
A necessidade mística de progenitura atingia em cheio as mulheres. Comparadas a terras estéreis, humilhadas pelos companheiros e pela comunidade, associadas a mulas - animais que, estéreis geneticamente, eram conduzidos pelos padres, estes estéreis (pelo menos teoricamente) por vocação -, a esterilidade feminina era vivida como uma tara ou um contra-senso. Ao inverter o ciclo das gerações, interrompendo as linhagens e contrariando os ciclos agrícolas e a natureza, à qual seu ciclo vital deveria comparar-se, a mulher estéril parecia ter o corpo entupido, fechado e prisioneiro de forças estranhas.

Além dos recursos devocionais a santa Ana e santa Comba, padroeiras da fertilidade conjugal, era preciso quebrar o obstáculo que obstruía a passagem da preciosa semente que poderia fecundá-la. As explicações médicas para os descaminhos fisiológicos do corpo faziam-se impregnadas de magia. As exigências do moderno casamento cristão, bem como as condições para sua dissolução, não pareciam, porém, penetrar as teorias sobre a infecundidade feminina. As dificuldades para reunir numa classificação os vários males "da madre", as anomalias de órgãos que não podiam ser examinados porque internos, e o mito da passividade feminina na procriação contribuíam para que o corpo feminino fosse encarado, segundo Lígia Bellini (1987), como uma "coisa obscura”.

Possuidora de "faculdades adormecidas, a madre devia despertar pela ação de piolhos e percevejos metidos no orifício do cano ... para que com mordeduras e movimentos que fazem excitem a faculdade repelente adormecida". Sua desobstrução se faria "metendo-lhe na boca uma pequena castanha-da-índia, furando-a e atando-a bem com fio de retrós e deixando-a estar quatro ou seis horas, porque não só provoca bem a conjunção, mas alimpa a madre de todos os maus humores que são quase sempre a causa de muitas mulheres não conceberem" (Semedo, 1707, p. 177).

As analogias com animais de grande fecundidade faziam sugerir receitas à base de "sal fixo de ratos e caldo de galo velho", por conceberem esses roedores "de uma só vez cinco ou seis ratinhos". Beber "pelo tempo de três meses água cozida com uma mão cheia de sálvias machucadas" era indicação do "virtuoso" padre Jerônimo Lobo, religioso da Companhia de Jesus, que, assim, aprendera no Japão. Feijão-fradinho tomado em jejum misturado à água ou ingerir óleo de copaíba, como sugeria João Ferreira da Roa em Pernambuco, no século XVII, "alimpava o útero de sordícies" que atrasavam a concepção (apud Osório de Andrade, 1956, p. 282). Piso (1948, p. 123), por sua vez, lembrava que do óleo em que se assavam "aqueles vermes que vivem nas palmeiras" deviam fazer-se emplastros colocados sobre o umbigo: "tem-se visto não vulgares efeitos destes e semelhantes remédios, e mulheres consideradas estéreis vieram a recobrar a vitalidade para si e para a geração".

"Achaques diabólicos contra a lei divina" atingiam também as mulheres estéreis, aconselhadas a pendurar "artemísia à entrada da 
porta” (Moura, apud São Paulo, 1936, p. 541) ou dissolver o malefício passando "esterco da pessoa amada no sapato direito"; a primeira que sentisse o fedor dissolveria o encantamento.

"Inimigo da saúde e da salvação das criaturas", "invejoso da paz e do sossego que logram na terra os que bem vivem", o demônio que obstaculizava a procriação tinha que ser rechaçado com defumações "das partes vergonhosas com os dentes de uma caveira" (Pereira, s. d. p. 52). Sua ação sobre a coisa obscura era imensa, posto que a mulher, como o demonstrou Delumeau (1978), era uma sua agente.

As histórias sobre esterilizações maléficas eram várias: "Se achou uma mulher nobre que estava tábida e consunta, a qual era fabricada de cera com um orifício em que estava engastada e metida a figura de um coração e na parte posterior escrito o nome da mulher" (Pereira, 1734, pp. 29-30). Outra vomitara

uns poucos cabelos enlaçados, um molho de rosetas agulhas e uma massa do tamanho de um ovo, do qual saiu multidão de formiguinhas que exalavam fedor tão horrendo que nenhum dos circundantes o podia tolerar. Com segundo vômito expulsou um animal como um punho negro, capiloso, com cauda grande e modo de rato que, depois de andar pela casa com muita presteza, morreu.

Para fugir ao estigma da esterilidade, elas ainda untavam seus genitais com "esterco de raposa" (idem, ibidem, p. 231) e sebo de vaca, portavam amuletos feitos com genital de lobo, dentes de "mínimo de sete anos", pedras de águia, além de rezar a santo Hilário, conhecido por seu "remédio para os casados terem filhos e afugentar o demônio" (Sequeira, 1754, p. 263).

A grande prole e o poder de gerá-la associavam-se às práticas de fecundidade, cujos restos, ou amostras, encontramos nas receitas mágicomedicinais inventariadas e "traduzidas" pelos doutores da época. Mulheres e doutores, por sua vez, movimentavam-se ao longo do Antigo Regime num mesmo continente. Aqueles drenando lentamente conhecimentos que se originaram num espaço especificamente feminino: o da cozinha, o do quintal, o da horta, onde, entre ervas, frutos e animais domésticos, as mulheres praticavam corriqueiramente um saber sobre as doenças, as feridas, as dores e a procriação. Reunidas empiricamente pelos doutores, tais receitas perdiam a especificidade, mas não deixavam de ser praticadas. Grande parte dessas fórmulas caseiras eram realizadas por comadres e parteiras, excluindo a intervenção do médico, que só se tornará decisiva no século XIX, com o avanço da obstetrícia.

Diferentemente de hoje, quando a pílula azul - o Viagra - tornouse assunto de medicina pública, nossos antepassados encaravam a impotência com profundo temor: medo do maligno, medo de feitiços, além do preconceito em sociedades tradicionais onde o "crescei e 
multiplicai-vos" era lei. Buscava-se, então, toda sorte de simpatia, remédio analógico ou mezinha milagrosa capaz de combater um mal capaz de ameaçar a função de homens e mulheres sobre a face da Terra. Resta saber se no entusiasmo com que se recebeu o Viagra não restam, ainda, traços desse quadro mental.

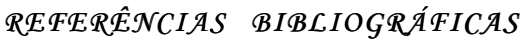

Abreu, Aleixo de

1629

Abreu, Brás Luís de 1726

Andrade, Mário de 1980

Araújo, Alceu

Maynard de

1961

Bajos, Nathalie e

Bozon, Michel juin 1999

Bellini, Lígia 1987

Camporesi, Piero 1990

Carneiro, Henrique 1994

Darmon, Pierre 1988

Darmon, Pierre 1981

Del Priore, Mary 1998

Delumeau, Jean 1978

Fernand, Jean 1623

Ferreira da Rosa, João 1956

Foucault, Michel

1976

Freyre, Gilberto

1980

Henriques, Francisco da Fonseca

1731
Tratado de las siete enfermidades.

Lisboa, Pedro Graasbeck.

Portugal médico ou monarquia médico lusitano prática, simbólica, ética e política. Lisboa, João Antunes.

Namoros com a medicina.

Belo Horizonte, Martins/Itatiaia.

Medicina rústica.

Rio de Janeiro, Companhia Editora Nacional.

'La sexualité à l'épreuve de la medicalisation: le Viagra'.

Actes de la Recherche en Sciences Sociales (Sur la sexualité), $\mathrm{n}^{0}$ 128, pp. 34-7.

A coisa obscura: mulher, sodomia e Inquisição no Brasil colonial.

São Paulo, Brasiliense.

Les baumes de l'amour.

Paris, Pluriel.

Filtros, mezinhas e triarcas: as drogas no mundo moderno.

São Paulo, Xamã.

O tribunal da impotência: virilidade e fracassos conjugais na França do Antigo Regime. Rio de Janeiro, Paz e Terra.

Le mythe de la procréation à l'âge baroque.

Paris, Seuil.

'Magia e medicina na Colônia: o corpo feminino'.

Em História das mulheres no Brasil. São Paulo, Unesp/Contexto.

La peur en Occident.

Paris, Fayard.

Traité de l'essence et guérison de l'amour.

Paris, Denys Moreu.

'Tratado único da constituição pestilencial de Pernambuco' (1636).

Em Gilberto Osório de Andrade, Morão, rosa e pimenta:

notícia dos três primeiros livros em vernáculo sobre a medicina no Brasil.

Recife, Arquivo Público Estadual.

Histoire de la sexualité I - La volonté de savoir.

Paris, Gallimard.

Casa-grande e senzala.

Rio de Janeiro, José Olympio.

Âncora medicinal para conservar a vida com saúde.

Lisboa, Miguel Rodrigues. 
Mello e Souza, Laura 1988

Moura, J. Ferreira de 1936

Orta, Garcia de 1891

Pereira, Bernardo s. d.

Pereira, Ruy dos Santos 1980

Piso, Guilherme 1948 (1르 ed. 1648)

Sabugo, Oliva D. de $\mathcal{N}$ antes Barreira 1734

Semedo, João Curvo 1720

Semedo, João Curvo 1707

Sequeira, Angelo 1754

Serrão, Joaquim Veríssimo s. d.
O diabo na Terra de Santa Cruz. São Paulo, Companhia das Letras.

Em Fernando São Paulo, Linguagem médica popular no Brasil. Rio de Janeiro, Barreto.

Colóquio dos simples, das drogas e das cousas medicinais da Índia. Lisboa, Academia Real das Ciências de Lisboa.

Anacephaleosis médico-teologica.

Lisboa, s.e.

Piso e a medicina indigena.

Recife, Instituto Arqueológico, Histórico e Geográfico de Pernambuco/UFPE.

História natural do Brasil ilustrado.

São Paulo, Nacional.

Nova filosofia da natureza do homem, não conhecida nem alcançada dos grandes filósofos antigos, a qual melhora a saúde e a vida humana.

Lisboa, Manuel Fernandes da Costa.

Atalaia da vida contra hostilidades da morte.

Lisboa, Oficina Ferreiriana.

Observações médico-doutrinais de cem gravissimos casos.

Lisboa, Antônio Pedroso Galvão.

Botica preciosa e tesouro precioso da Lapa.

Lisboa, Miguel Rodrigues.

História de Portugal (1640-1750).

Lisboa, Verbo, vol. V.

Recebido para publicação em setembro de 2000. Aprovado para publicação em fevereiro de 2001. 